\title{
THE FWF'S OPEN ACCESS POLICY OVER THE LAST 15 YEARS - DEVELOPMENTS AND OUTLOOK
}

\section{by Katharina Rieck}

\begin{abstract}
The report outlines the developments of the open access (OA) policy of the Austrian Science Fund (FWF) since its first release in 2004. Over the last 15 years, the FWF has not only continuously updated its OA policy but has also adapted its support mechanisms to include dedicated funding programmes and financial support structures for alternative publication venues and infrastructures. A brief analysis of the FWF's open access funding will be provided in the second part of the article, which will conclude with an outlook of the upcoming revisions to the OA policy.
\end{abstract}

Keywords: Open Access; Open Data; Open Science; Scholarly Communication; Research funding; Austria

\section{DIE OPEN ACCESS POLICY DES FWF ÜBER DIE LETZTEN 15 JAHRE - ENTWICKLUNGEN UND AUSBLICK}

Zusammenfassung: Der Bericht skizziert die Entwicklungen der Open-Access (OA) Policy des österreichischen Wissenschaftsfonds (FWF) seit der ersten Veröffentlichung im Jahr 2004. Der FWF hat seine Policy in den letzten 15 Jahren nicht nur kontinuierlich überarbeitet, sondern auch seine Fördermechanismen wie spezielle Förderprogramme und finanzielle Unterstützungsstrukturen für alternative Publikationsformate und Infrastrukturen angepasst. Im zweiten Teil des Berichts wird eine kurze Analyse der FWF-Finanzierung von Open Access vorgenommen und ein Ausblick auf anstehende Anpassungen der OA Policy gegeben.

Schlagwörter: Open Access; Open Data; Open Science; Scholarly Communication; Wissenschaftsförderung; Österreich

DOI: https://doi.org/10.31263/voebm.v72i2.2837

(C) Katharina Rieck

Dieses Werk ist lizenziert unter einer

Creative-Commons-Lizenz Namensnennung 4.0 International 
First released on Zenodo on May 21, 2019; see: Katharina Rieck (2019). The FWF's Open Access Policy over the Last 15 Years - Developments and Outlook. Zenodo. http://doi.org/10.5281/zenodo.3060200.

\section{Contents}

1. Introduction

2. FWF's OA policy developments

3. $O A$ initiatives and collaborations

4. FWF's OA funding

5. Policy compliance

6. Further developments and outlook

7. References

\section{Introduction}

For the past 15 years, the Austrian Science Fund (FWF) has actively supported Open Access (OA) to the outputs of publicly-funded research projects in Austria. The FWF is committed to ensuring that research outcomes are not locked behind paywalls but freely accessible for everyone on the internet. As one of the first funding organisations worldwide that introduced an OA mandate for publications, the FWF can say today that almost all publications resulting from its funded grants are openly available and free to read for everyone online. This high percentage of OA is the result of the FWF's continuing OA policy developments and support of OA initiatives over the past years.

As a member of cOAlition $\mathrm{S}^{1}$, the FWF will publish a revised version of its current OA policy to publications in the near future which will then be consistent with Plan S. These preparations have prompted the Austrian Science Fund (FWF) to reflect on the developments of its OA policy and on supporting activities in the field of open scholarship over the last 15 years.

\section{FWF's OA policy developments}

In 2003, the Austrian Science Fund (FWF) was one of the first signatories of the Berlin Declaration on Open Access to Knowledge in the Sciences and Huma- 
nities $^{2}$, which is today regarded as being one of the founding documents of the international OA movement. One year later, the FWF released its first OA policy in 2004 and has since updated the original version of the policy three times.

The first version of the FWF's OA policy was a strong recommendation for OA to FWF-funded project outputs and not a mandate. FWF-funded researchers were strongly encouraged to make their publications $O A$ and thanks to the Peer-reviewed Publications programme were able to receive additional financial support to do so (for financial support structures, see section 4).

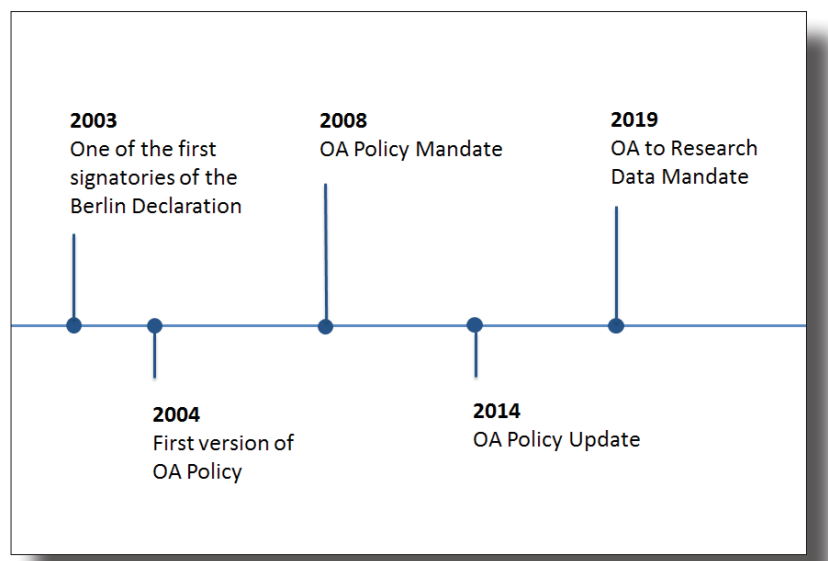

Fig. 1: FWF's Open Access policy developments

In accordance with the Berlin Declaration, which makes clear that "(o)pen access contributions include original scientific research results, raw data and metadata, source materials, digital representations of pictorial and graphical materials and scholarly multimedia material,"3 the FWF's OA policy has included a dedicated section on research data since 2004. Research data and similar materials that resulted from FWF grants were strongly recommended to be made openly accessible.

In 2008, OA became a requirement for all peer-reviewed publications ${ }^{4}$ resulting from FWF projects. The second version of the policy ${ }^{5}$ comprised two strategies for making research publications openly available: immediate OA in a journal - either in an OA journal (Gold OA) or in a hybrid OA journal - or OA via self-archiving of the author's accepted manuscript in a discipline-specific or institutional repository no longer than six to 12 months after publication (Green OA). Regardless of the 
publication venue, publications had to be archived in a registered repository. The policy also included a dedicated section on research data, which at this point continued to be a strong recommendation. OA to research data was encouraged whenever legally and ethically possible by depositing the data in a way that made it citeable and re-useable without restrictions for others.

This policy version was in place from 2008 until the end of 2014. One year after the FWF signed the DORA declaration in $2013^{6}$, an updated version - the third policy version - of the FWF's OA policy went into effect for all publications resulting from projects that were granted FWF funding after November 2014. The policy included sections that specified the different OA publishing options. Gold OA journals have since then been required to be listed in the Directory of OA Journals (DOAJ) and hybrid OA journals in the Web of Science or Scopus. In any case, publications must be made available using the Creative Commons Attribution CC-BY licence. Together with the policy update, the guidelines for the financial support of OA publications as part of the Peer-reviewed Publications programme were adopted (see below). Green OA continued to be an option and since then can be ensured by self-deposition of the author's accepted manuscript in a registered discipline-specific or institutional repository no longer than 12 months after publication. OA to research data continued to be a strong recommendation but was not a mandate at this time. In 2015, the EU funded PASTEUR4OA project ${ }^{7}$ published a funder case study highlighting the FWF's policy developments and declaring it one of the most effective ones worldwide. ${ }^{8}$

The most recent OA policy update took place at the beginning of 2019 when OA to research data became a mandate for research data underlying publications. As of 2019, the FWF's open access policy is comprised of two parts: OA to Peer-reviewed Publications ${ }^{9}$ and $\mathrm{OA}$ to Research Data. ${ }^{10}$ Based on the experiences gained as part of the FWF's Open Research Data pilot programme ${ }^{11}$ and the exchange via the Science Europe working group on research data ${ }^{12}$ on an international level and via the e-infrastructures plus project ${ }^{13}$ on a national level, the FWF has updated its OA policy on research data. As of 1 January 2019, the FWF requires OA to research data that underlie scholarly publications whenever it is legally, ethically, and technically possible to ensure the reproducibility and reuse of research outcomes resulting from FWF-funded projects. Furthermore, the FWF asks all grantees to submit a research data management plan. ${ }^{14}$ 


\section{OA initiatives and collaborations}

The FWF's policy developments have been supported by various initiatives such as the journal funding pilot programme in 2013, which provided funding for eight high-quality OA journals in the social sciences and humanities. ${ }^{15}$ The evaluation of the programme provided valuable insights into the technical and structural challenges media owners have to face when flipping a journal to OA or publishing a new OA journal.

Furthermore, in 2012, the FWF, together with Universities Austria (uniko), founded the Open Access Network Austria (OANA), which is now known as Open Science Network Austria. ${ }^{16}$ OANA is a think tank that aims to bring together national stakeholders to discuss issues regarding Open Science in Austria. The network published for example the "Recommendations for the Transition to OA in Austria"17 in 2015, which describes 16 steps that have to be undertaken to ensure 100\% OA in Austria by 2025, and the "Vienna Principles - A Vision for Scholarly Communication." 18 Currently, OANA is, among other things, working on recommendations for an Open Science strategy for Austria. ${ }^{19}$

During the last few years, the FWF has also supported various national and international Open Science initiatives and is for example a signatory of the OA2020 Expression of Interest ${ }^{20}$, the EOSC declaration ${ }^{21}$, and the ORCID open letter of funders ${ }^{22}$.

\section{FWF's OA funding}

Since 1968, the founding year of the Austrian Science Fund, the FWF has provided financial support for publication costs. ${ }^{23}$ Until 2004, the FWF's „Druckkosten“ (printing costs) support was mainly used to subsidise printing costs for monographs or edited volumes from the Social Sciences and Humanities. From 1968 to 2004, the costs continuously rose and amounted to an average of EUR 15,000.- per book. Those costs were charged even though there was usually no copy-editing service provided by the publishers, and the international peer review was organised by the FWF. Therefore, in 2005, the FWF capped its grants for stand-alone publications to EUR 8,000.- in book processing charges (BPCs). Only in exceptional cases was granted a higher funding (up to EUR 15,000.-).

In 2009, the support for book publications was renamed to "StandAlone Publications programme" 24 and the cap was lifted on the condition that the publishers would offer other services in addition to printing, such 
as translations and OA. Even though the FWF did not have a mandate for OA to book publications in place in 2009, two-thirds of the books were already published OA between 2009 and 2012. From 2012 onward, OA to stand-alone publications with a Creative Commons licence (CC BY, CCBY-NC, CC-BY-ND, CC-BY-NC-ND) and archiving of monographs in the FWF's E-Book Library were mandatory. Since 2014, the costs spent as part of the Stand-Alone Publications programme have been published online ${ }^{25}$, and books must be published under the CC BY or CC BY-NC licence. From 2014-2018, the BPCs continuously decreased so that at present, the average BPC is around EUR 13,000.- per book but includes far more services for authors than when the programme initially started.

\begin{tabular}{|c|c|c|c|}
\hline $\begin{array}{c}\text { Year of } \\
\text { FWF Payment }\end{array}$ & $\begin{array}{c}\text { BPCs } \\
\text { in EUR }\end{array}$ & $\begin{array}{c}\text { No. of } \\
\text { Publications }\end{array}$ & $\begin{array}{c}\text { Average BPC } \\
\text { in EUR }\end{array}$ \\
\hline $\mathbf{2 0 1 4}$ & $957,139.68$ & 62 & $15,437.74$ \\
\hline $\mathbf{2 0 1 5}$ & $689,737.00$ & 48 & $14,369.52$ \\
\hline $\mathbf{2 0 1 6}$ & $547,688.60$ & 37 & $14,802.39$ \\
\hline $\mathbf{2 0 1 7}$ & $611,719.32$ & 44 & $13,902.71$ \\
\hline $\mathbf{2 0 1 8}$ & $505,767.28$ & 39 & $12,968.39$ \\
\hline Total & $\mathbf{3 , 3 1 2 , 0 5 1 . 8 8}$ & $\mathbf{2 3 0}$ & $\mathbf{1 4 , 4 0 0 . 2 6}$ \\
\hline
\end{tabular}

Tab. 1: FWF costs spent as part of the Stand-Alone Publications programme 2014-2018

In 2016, the programme was extended to the funding of innovative publication formats such as annotated scholarly databases, web-based publications, etc. Currently, the publications funded as part of the programme must be published under the CC BY or CC-BY-NC licence (a mandate for the CC BY licence was in place from 2015 to the end of 2018). For publications with the more restrictive licence CC BY-NC, the FWF will, however, provide less funding than for publications with a CC BY licence.

Today, around $726^{26}$ funded stand-alone publications are openly-accessible via and archived in the FWF's E-Book Library ${ }^{27}$ as well as indexed in the OAPEN Library ${ }^{28}$ and the Directory of Open Access Books (DOAB) ${ }^{29}$. The impact of the FWF's E-Book Library Collection in the OAPEN Library was analysed in 2015. ${ }^{30}$ The results showed that the books reach readers far beyond Austria and the German-speaking community. Hence, the value of supporting OA to books by FWF is evident.

From 2000 onward, the FWF not only financially supported book publications but also page, figure, and colour charges for articles in scho- 
larly journals that resulted from FWF projects. Until 2004, the FWF spent around EUR 200,000.- per year on such subsidies, of which two-thirds resulted from publications in the Life Sciences and one-third from the $\mathrm{Na}$ tural Sciences. Together with the OA policy release in 2004, the Peer-reviewed Publications programme ${ }^{31}$ was introduced to provide FWF-funded researchers with additional financial resources to cover the costs of OA articles and other publication costs up to three years after a grant ended. The results of the "Developing an Effective Market for Article Processing Charges" study ${ }^{32}$, which had been commissioned by the FWF together with the Wellcome Trust and other international organisations, led to an update of the publication funding scheme, which means that since November 2014, the FWF has only financially supported immediate OA publications with a CC BY licence. Costs such as page, colour, or figure charges are no longer subsidized. Furthermore, price caps for Gold OA (EUR 2,500.-) and Hybrid OA (EUR 1,500.-) have been introduced.

For the last six years (from 2013 onward), the FWF has monitored and published its publication cost expenditures from both programmes online on Zenodo. ${ }^{33}$ The data from the Peer-reviewed Publications programme is additionally included in the Open APC dataset to allow for international cost monitoring. ${ }^{34}$

In total, from 2013 to $2018^{35}$, the FWF financially supported 8,211 article items ${ }^{36}$ at a cost of EUR $16.9 \mathrm{~m}$ as part of the Peer-reviewed Publications programme.

\begin{tabular}{|c|c|c|c|c|c|c|c|c|}
\hline $\begin{array}{c}\text { Year of } \\
\text { FWF } \\
\text { Payment }\end{array}$ & $\begin{array}{c}\text { Gold OA } \\
\text { in EUR }\end{array}$ & Items & $\begin{array}{c}\text { Hybrid OA } \\
\text { in EUR }\end{array}$ & Items & $\begin{array}{c}\text { Other Costs } \\
\text { in EUR }\end{array}$ & Items & $\begin{array}{c}\text { Total } \\
\text { in EUR }\end{array}$ & Items \\
\hline $\mathbf{2 0 1 3}$ & $284,515.64$ & 202 & $2,087,664.65$ & 918 & $272,991.25$ & 246 & $2,645,171.54$ & 1,366 \\
\hline $\mathbf{2 0 1 4}$ & $319,345.79$ & 248 & $1,797,936.56$ & 782 & $339,064.13$ & 285 & $2,456,346.48$ & 1,315 \\
\hline $\mathbf{2 0 1 5}$ & $418,408.05$ & 288 & $2,376,355.58$ & 912 & $273,653.57$ & 215 & $3,068,417.20$ & 1,415 \\
\hline $\mathbf{2 0 1 6}$ & $440,782.60$ & 247 & $2,030,398.63$ & 840 & $205,913.21$ & 156 & $2,677,094.44$ & 1,243 \\
\hline $\mathbf{2 0 1 7}$ & $704,560.97$ & 354 & $1,898,729.94$ & 790 & $127,602.05$ & 103 & $2,730,892.96$ & 1,247 \\
\hline $\mathbf{2 0 1 8}$ & $800,833.32$ & 415 & $2,398,469.65$ & 1,115 & $115,031.27$ & 95 & $3,314,334.24$ & 1,625 \\
\hline Total & $\mathbf{2 , 9 6 8 , 4 4 6 . 3 7}$ & $\mathbf{1 7 5 4}$ & $\mathbf{1 2 , 5 8 9 , 5 5 5 . 0 1}$ & $\mathbf{5 3 5 7}$ & $\mathbf{1 , 3 3 4 , 2 5 5 . 4 8}$ & $\mathbf{1 , 1 0 0}$ & $\mathbf{1 6 , 8 9 2 , 2 5 6 . 8 6}$ & $\mathbf{8 , 2 1 1}$ \\
\hline
\end{tabular}

Tab. 2: FWF costs spent as part of the Peer-reviewed Publications programme 2013-2018

The publishers with the highest shares during the last six years are three of the major commercial academic publishers: Elsevier, Springer Nature, and 
Wiley-Blackwell. The first three alone account for $56 \%$ of all costs spent by the FWF as part of the Peer-reviewed Publications programme between the years 2013 and 2018.

Since 2014, the cost data has included information on the publication costs per discipline. The data from 2014 to 2018 shows that the Life Sciences hold the highest share with $57 \%$, followed by the Natural Sciences with $37 \%$, and that the Social Sciences and the Humanities only make up $6 \%$ of the overall costs.

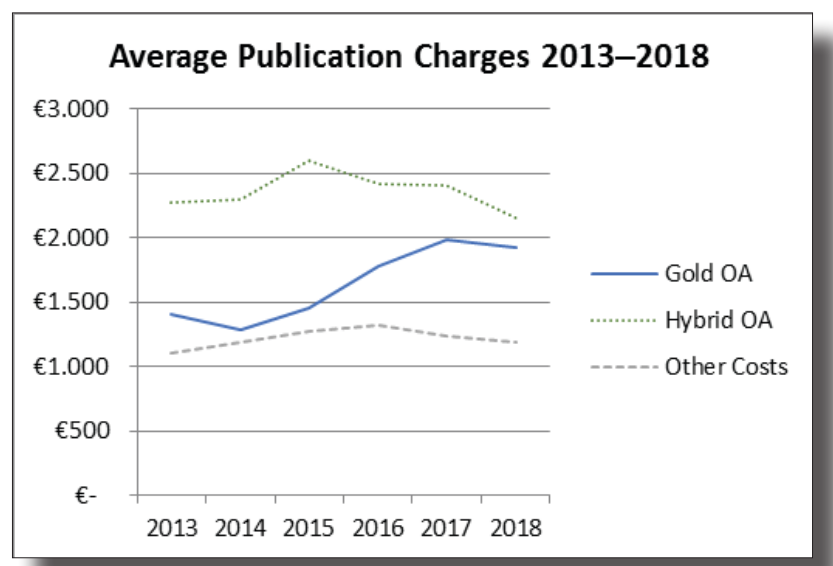

Fig. 2: Average publication charges 2013-2018

\begin{tabular}{|c|c|c|c|}
\hline Year & $\begin{array}{c}\text { Gold OA } \\
\text { in EUR }\end{array}$ & $\begin{array}{c}\text { Hybrid OA } \\
\text { in EUR }\end{array}$ & $\begin{array}{c}\text { Other Costs } \\
\text { in EUR }\end{array}$ \\
\hline $\mathbf{2 0 1 3}$ & $1,408.49$ & $2,274.14$ & $1,109.72$ \\
\hline $\mathbf{2 0 1 4}$ & $1,287.68$ & $2,299.15$ & $1,189.70$ \\
\hline $\mathbf{2 0 1 5}$ & $1,452.81$ & $2,605.65$ & $1,272.81$ \\
\hline $\mathbf{2 0 1 6}$ & $1,784.54$ & $2,417.14$ & $1,319.96$ \\
\hline $\mathbf{2 0 1 7}$ & $1,990.29$ & $2,403.46$ & $1,238.85$ \\
\hline $\mathbf{2 0 1 8}$ & $1,929.72$ & $2,151.09$ & $1,186.28$ \\
\hline
\end{tabular}

Tab. 3: Average publication charges 2013-2018

Figure 2 and Table 3 show two trends: First, the increase of the average APC for Gold OA, for which the FWF had introduced a price cap of EUR 2,500.- in 2014. The average APC in this regard in 2018 was $37 \%$ higher than in the year 2013. The data of the Wellcome Trust ${ }^{37}$ shows a similar 
cost increase for Gold OA between 2015/2016 and 2017/2018 with average APCs of EUR 2,412.32.- ${ }^{38} / £ 2,090$.- (or EUR 1,959.87.-/£ 1,698.when excluding the higher priced OA journal APCs) in 2017/2018. In comparison to the data of FWF and Wellcome, the average APC for Gold OA on the Open APC ${ }^{39}$ platform is lower, at EUR 1,558.- ${ }^{40}$. The development of the Gold OA APCs needs to be further monitored in the upcoming years to be able to better understand the OA cost trends and to be able to react to the market developments.

The second trend that can be seen is the decrease of average Hybrid OA costs after 2015. The decline in costs can be explained by the price cap of EUR 1,500.-, which was introduced for publications resulting from projects which were granted after 1 November 2014, and the transformative agreements that are in place with some of the major publishers (for details, see below). The "price cap effect" was not visible in the data of the first years after the new policy was introduced but gained more influence on the cost developments from 2016 onward.

It is important to note that FWF-funded principal investigators can use other financial resources, such as institutional budgets or cost-sharing with co-authors, to cover the costs that exceed the FWF's price cap. Where the additional money is coming from cannot be monitored by the FWF. The same applies for other costs, such as page, colour, or figure charges, which the FWF stopped funding with the 2014 policy update. To be able to monitor the total costs of OA articles, the FWF is working together with Austrian research institutions as part of the national project Austrian Transition to OA (AT2OA) ${ }^{41}$ and the international initiatives Efficiency and Standards for Article Charges (ESAC) ${ }^{42}$ and Open APC.

Since 2014, the FWF, together with the Austrian Academic Library Consortium (KEMÖ) ${ }^{43}$, has negotiated transformative OA agreements (offsetting as well as read and publish agreements) with publishers. So far, transformative agreements have been reached with four of the six publishers for which the FWF has spent the most in recent years (with IOP Publishing, Taylor \& Francis, Springer Nature, and Wiley). In 2018, the share of publication costs that the FWF spent as part of those four transformative arrangements amounted to EUR 0.98 m for 506 article items. Additionally, there are agreements with the Gold OA publishers Frontiers ${ }^{44}$ and $\mathrm{MDPI}^{45}$ in place that allow for discounted publishing and simpler workflows for FWF-funded authors. The texts of those agreements are openly available online. ${ }^{46}$

Empirical evidence shows that already in $201350 \%$ of all research publications worldwide were published with only five publishers. ${ }^{47}$ Hence, to foster a diverse OA publishing market, since 2014, the FWF has also been 
supporting alternative publication models and infrastructures ${ }^{48}$, such as SCOAP3, Europe PMC, arxiv, DOAJ, OAPEN, OLH, ORCID, and SciPost. The costs spent on these initiatives are published on the FWF's website on a yearly basis. ${ }^{49}$

Based on the cost data for 2018, the FWF altogether spent EUR $3.94 \mathrm{~m}$ on publication costs as part of the Peer-reviewed Publications programme, the Stand-Alone Publications programme, and alternative publication venues and infrastructures. EUR $2.33 \mathrm{~m}$ was spent on APC payments to publishers or reimbursements to FWF grant holders, and EUR $0.98 \mathrm{~m}$ as part of transformative agreements. An additional EUR $0.50 \mathrm{~m}$ was spent on stand-alone publications. The support for alternative publication models and infrastructures amounted to EUR $0.13 \mathrm{~m}$. In total, this amounts to about $1.7 \%$ of the FWF's annual budget.

\section{Policy compliance}

Since 2015, the FWF has been monitoring the publication output of FWF projects and the compliance with its OA policy. The FWF's OA compliance report for 2018 shows that $92 \%$ of all peer-reviewed publications resulting from FWF projects are OA, a rise of compliance in comparison to last year's $90 \%$ (2015: $83 \%$, 2016: 92\%). The data refers to peer-reviewed publications that arose from FWF grants and which are listed in the project's final reports. ${ }^{50}$ The FWF data supports the results of a recent study that provides empirical evidence that "(...) funders can clearly shape compliance through their mandates, and that this compliance needs to be monitored (...) when the proper structure and incentives are in place, researchers comply." 51

Despite the FWF's OA compliance rate of over $90 \%$ in the last years at the national level and studies estimating that almost $50 \%$ of all scholarly publications worldwide are already $\mathrm{OA}^{52}$, many international stakeholders claim that the uptake of OA since the release of the Berlin Declaration in 2003 has been too slow and therefore have been looking for ways to speed up the transition to an OA world.

\section{Further developments and outlook}

Probably the most prominent initiative in recent months to promote the flip to OA has been Plan S. The FWF is one of the initial members of cOAlition $S^{53}$, an international consortium of research funders that supports 
Plan $\mathrm{S}^{54}$, which was initiated in 2018 and aims for immediate OA to publications funded by its members. Long before Plan $S$ was published on 4 September 2018, former FWF president Christoph Kratky had already advocated for a coordinated approach in 2013 and called it a key principle for OA: 55 "Only through close cooperation, starting at a European level, can we develop and implement models to accelerate the transition to full OA." It would take five more years before such a coordinated action was initiated with cOAlition S in 2018.

In November 2018, the Plan S implementation guidance was published, which detailed the principles and received more than 600 international feedbacks. ${ }^{56}$ Plan $\mathrm{S}$ has led to one of the most extensive international discussions concerning the current scholarly communication ecosystem and OA since the beginning of the OA movement. A revised version of the Plan $S$ guidance document was published in May 2019. ${ }^{57}$ This updated version will eventually have an impact on the FWF's current OA policy and will lead to revisions of it in the next months. In addition to requiring changes to the OA policy, Plan S will also have an impact on the FWF's funding of $\mathrm{OA}$. Details will also be published in the upcoming months. However, the FWF, with its current OA policy and its close cooperation with Austrian research institutions and KEMÖ, is well prepared for Plan S. Plan S elements such as a requirement for a CC BY licence for publications, transformative agreements, support of alternative open access journals and platforms, coverage of publication costs, and monitoring of OA - costs and compliance - have been integral parts of the FWF's OA policy since 2014.

The FWF's 15 years of experience with its OA policy will help to implement an updated, Plan S-compliant OA policy on publications in the next months and any further revisions that may be necessary to the OA policy on research data in the future. Close collaboration with national and international partners, the monitoring of OA costs and OA compliance, as well as an openness for and support of new Open Science initiatives have proven to be key factors in successfully updating the respective policies in a rapidly changing environment like the scholarly communication landscape of the $21^{\text {st }}$ century.

Katharina Rieck MA, M.A. (LIS) ORCID: https://orcid.org/0000-0002-9316-165X FWF Der Wissenschaftsfonds E-Mail: katharina.rieck@fwf.ac.at 


\section{References}

Aichner C. (2007): 40 Jahre im Dienste der Forschung. Gründung und Geschichte des Fonds zur Förderung der wissenschaftlichen Forschung (1967-2007). Diplomarbeit. https://m.fwf.ac.at/fileadmin/files/Dokumente/News_Presse/Veranstaltungsrueckblick/2007/10_40_Jahre_ FWF/aichner.pdf

Archambault É et al. (2014): Proportion of open access papers published in peer-reviewed journals at the European and world levels - 19962013. http://science-metrix.com/sites/default/files/science-metrix/publications/d_1.8_sm_ec_dg-rtd_proportion_oa_1996-2013_v11p.pdf Bauer et al. (2013): Open Access Bestandsaufnahme an österreichischen Universitäten - Ergebnisse einer Umfrage im Auftrag des Forums Universitätsbibliotheken Österreichs (UBIFO). Mitteilungen der Vereinigung Österreichischer Bibliothekarinnen \& Bibliothekare 66(3/4), 535558. http://eprints.rclis.org/20968/

Bauer B. et al. (2015): Recommendations for the Transition to Open Access in Austria. Zenodo. http://doi.org/10.5281/zenodo.34079

Björk BC., Solomon D. (2012): Open access versus subscription journals: a comparison of scientific impact. BMC Medicine 10, 73. https://doi. org/10.1186/1741-7015-10-73

Ferus A., Reckling F. (2019): Die Förderung von alternativen, nicht-kommerziellen Open Science-Infrastrukturen \& -Services (OSIS) durch Forschungseinrichtungen in Österreich - Empfehlungen, Kriterien \& Modelle. Mitteilungen der Vereinigung Österreichischer Bibliothekarinnen und Bibliothekare 72(1), 89-105. https://doi.org/10.31263/ voebm.v72i1.2279

FWF (2008): Open Access Policy bei FWF-Projekten. FWF INFO. Das Informationsmagazin des Wissenschaftsfonds. https://www.fwf.ac.at/ fileadmin/files/Dokumente/info-Magazin/info64-08-01.pdf

Kratky C. (2013): A coordinated approach is key for OA. Nature 500, 503. https://doi.org/10.1038/500503a

Larivière V. et al. (2015): The Oligopoly of Academic Publishers in the Digital Era. PLoS ONE 10(6): e0127502. https://doi.org/10.1371/journal. pone. 0127502

Larivière V., Sugimoto C. (2018): Do authors comply when funders enforce OA to research? Nature 562, 483-486. http://doi.org/10.1038/ d41586-018-07101-w

Matt I. et al. (2017): Austrian Science Fund (FWF) Open Research Data (ORD) Pilot Report. https://doi.org/10.5281/zenodo.803234 
OAPEN Foundation \& Austrian Science Fund (2017): OAPEN usage report for open access books funded by the Austrian Science Fund (FWF) 2014-2016. Zenodo. http://doi.org/10.5281/zenodo.375810

Pinhasi R. et al. (2018): The weakest link - workflows in OA agreements: the experience of the Vienna University Library and recommendations for future negotiations. Insights 31, 27. https://doi.org/10.1629/ uksg.419

Piwowar $\mathrm{H}$ et al. (2018): The state of OA: a large-scale analysis of the prevalence and impact of Open Access articles. PeerJ 6, e4375. https:// doi.org/10.7717/peerj.4375

Reckling F. et al.: Report on the FWF OA Journal Funding Initiative (2018). Zenodo. http://doi.org/10.5281/zenodo.1433992

Snijder R. (2015): Evaluating the Impact of the FWF-E-Book-Library Collection in the OAPEN Library, D-Lib Magazine 21(7/8). https://doi. org/10.1045/july2015-snijder

Tonto Y. et al. (2015): Open Access Policies of Research Funders: The Case Study of the Austrian Science Fund (FWF). Zenodo. http://doi. org/10.5281/zenodo.35616

1 https://www.coalition-s.org/

2 https://openaccess.mpg.de/319790/Signatories

3 https://openaccess.mpg.de/Berlin-Declaration

4 The guidelines for stand-alone publications specify the OA conditions for book publications and differ timeline-wise from the ones for peerreviewed scholarly articles.

5 The policy was posted on the FWF website, and the FWF also published an article about the new requirement in its information magazine: FWF (2008): Open Access Policy bei FWF-Projekten. FWF INFO. Das Informationsmagazin des Wissenschaftsfonds, 11-14. https://www. fwf.ac.at/fileadmin/files/Dokumente/info-Magazin/info64-08-01.pdf; The magazine is no longer published by the FWF and has been replaced by the online blog Scilog: https://scilog.fwf.ac.at

6 https://sfdora.org/signers/

7 https://www.pasteur4oa.eu

8 Tonto et al. (2015): Open Access Policies of Research Funders: The Case Study of the Austrian Science Fund (FWF). Zenodo. http://doi. org/10.5281/zenodo.35616

9 https://www.fwf.ac.at/en/research-funding/open-access-policy/ open-access-to-peer-reviewed-publications/

10 https://www.fwf.ac.at/en/research-funding/open-access-policy/ 
open-access-to-research-data/

11 Matt I. et al. (2017): Austrian Science Fund (FWF) Open Research Data (ORD) Pilot Report. Zenodo. https://doi.org/10.5281/zenodo. 803234

12 https://www.scienceeurope.org/policy/policy-areas/research-data/

13 https://www.e-infrastructures.at/de/

14 https://www.fwf.ac.at/en/research-funding/open-access-policy/research-data-management/

15 Reckling F. et al. (2018): Report on the FWF OA Journal Funding Initiative. Zenodo. http://doi.org/10.5281/zenodo.1433993

16 https://oana.at/

17 Bauer B. et al. (2015): Recommendations for the Transition to Open Access in Austria. Zenodo. http://doi.org/10.5281/zenodo.34079

18 Kraker P. et al. (2016): The Vienna Principles: A Vision for Scholarly Communication in the 21 st Century. Zenodo. http://doi.org/10.5281/ zenodo.55597 and https://viennaprinciples.org

19 https://www.oana.at/arbeitsgruppen/ag-open-science-strategie/\#c310661

20 https://oa2020.org/mission/

21 https://ec.europa.eu/research/openscience/pdf/list_of_institutions_ endorsing_the_eosc_declaration.pdf

22 https://orcid.org/organizations/funders/open-letter

23 Aichner C. (2007): 40 Jahre im Dienste der Forschung. Gründung und Geschichte des Fonds zur Förderung der wissenschaftlichen Forschung (1967-2007), 166. https://m.fwf.ac.at/fileadmin/files/Dokumente/ News_Presse/Veranstaltungsrueckblick/2007/10_40_Jahre_FWF/aichner.pdf

24 https://www.fwf.ac.at/en/research-funding/fwf-programmes/ stand-alone-publications/

25 For FWF Publication Cost Data see: https://zenodo.org/search?page $=1 \&$ size $=20 \& q=$ austrian $\% 20$ science $\% 20$ fund

26 Information retrieved online at https://e-book.fwf.ac.at/\#?page=1\&pagesize $=10$ on $24-04-2019$

27 https://e-book.fwf.ac.at/\#?page=1\&pagesize $=10$

28 http://www.oapen.org/home

29 https://www.doabooks.org/

30 Snijder R. (2015): Evaluating the Impact of the FWF-E-Book-Library Collection in the OAPEN Library, D-Lib Magazine 21(7/8). https://doi. org/10.1045/july2015-snijder; an additional analysis of the OAPEN usage data was performed in 2017: OAPEN Foundation \& Austrian Sci- 
ence Fund (2017): OAPEN usage report for open access books funded by the Austrian Science Fund (FWF) 2014-2016. Zenodo. http://doi. org/10.5281/zenodo.375810

31 https://www.fwf.ac.at/en/research-funding/fwf-programmes/peer-reviewed-publications/

32 Björk BC., Solomon D. (2014): Developing an Effective Market for Open Access Article Processing Charges. https://wellcome.ac.uk/sites/ default/files/developing-effective-market-for-open-access-article-processing-charges-mar14.pdf

33 For FWF publication cost data see: https://zenodo.org/communities/ fwf $/$ ? page $=1 \&$ size $=20$

34 FWF data on Open APC: https://treemaps.intact-project.org/apcdata/openapc/\#institution/FWF\%20-\%20Austrian\%20Science\%20 Fund/

35 For the respective analysis, the FWF datasets from 2013 to 2018 that are published on Zenodo were merged and the data on funding as part of the Peer-reviewed Publications programme was used. All costs include taxes.

36 In this context, article refers to "cost item." More than one cost item can arise per article (e.g., OA charges and figure charges).

37 https://wellcome.ac.uk/funding/wellcome-and-coaf-open-accessspend-201718

38 Converted via OANDA https://www.oanda.com/lang/de/currency/ converter/ on 24-04-2019

39 https://treemaps.intact-project.org/apcdata/openapc/

40 https://treemaps.intact-project.org/apcdata/openapc/\#institution/ is_hybrid=FALSE (24-04-2019)

41 https://at2oa.at/en/home.html

42 https://esac-initiative.org

43 Pinhasi R. et al (2018): The weakest link - workflows in OA agreements: the experience of the Vienna University Library and recommendations for future negotiations. Insights 31, 27. https://doi.org/10.1629/uksg.419 44 http://doi.org/10.5281/zenodo.1118688

45 http://doi.org/10.5281/zenodo. 2536007

46 Frontiers (2017): Open-Access Publishing Framework Agreement For Austrian Research Performing and Research Funding Institutions. Zenodo. http://doi.org/10.5281/zenodo.1118688, and MDPI, Head Office of the Austrian Academic Library Consortium (KEMÖ), \& Austrian Science Fund (FWF) (2019): Open Access Agreement between members of the Austrian Academic Library Consortium (KEMÖ), the Austri- 
an Science Fund (FWF), and MDPI. Zenodo. http://doi.org/10.5281/ zenodo. 2536007

47 Larivière V. et al. (2015): The Oligopoly of Academic Publishers in the Digital Era. PLoS ONE 10(6): e0127502. https://doi.org/10.1371/ journal.pone.0127502

48 See: https://www.fwf.ac.at/en/research-funding/open-access-policy/ open-access-publication-models/; for all of Austria please see: Ferus A., Reckling F. (2019): Die Förderung von alternativen, nicht-kommerziellen Open Science-Infrastrukturen \& -Services (OSIS) durch Forschungseinrichtungen in Österreich - Empfehlungen, Kriterien \& Modelle. Mitteilungen der Vereinigung Österreichischer Bibliothekarinnen und Bibliothekare 72(1), 89-105. https://doi.org/10.31263/voebm.v72i1.2279

49 https://www.fwf.ac.at/en/research-funding/open-access-policy/ open-access-to-peer-reviewed-publications/open-access-publication-models/

50 The data will be available on Zenodo in spring 2019. For data on the previous years see: https://zenodo.org/communities/fwf/?page $=1 \&$ size $=20$

51 Larivière V., Sugimoto C. (2018): Do authors comply when funders enforce OA to research? Nature 562, 483-486. http://doi.org/10.1038/ d41586-018-07101-w

52 Piwowar $\mathrm{H}$ et al. (2018): The state of OA: a large-scale analysis of the prevalence and impact of Open Access articles. PeerJ 6, e4375. https:// doi.org/10.7717/peerj.4375; Archambault É et al. (2014): Proportion of open access papers published in peer-reviewed journals at the European and world levels-1996-2013. http://science-metrix.com/sites/ default/files/science-metrix/publications/d_1.8_sm_ec_dg-rtd_proportion_oa_1996-2013_v11p.pdf

53 https://www.coalition-s.org/

54 https://www.coalition-s.org/10-principles/

55 Kratky C. (2013): A coordinated approach is key for OA. Nature 500, 503. https://doi.org/10.1038/500503a

56 https://www.coalition-s.org/feedback/

57 https://www.coalition-s.org/revised-implementation-guidance/ 